\title{
CONSTRUCTION DELAY AND DISRUPTION CLAIMS ASSISTED THROUGH BIM TECHNOLOGY
}

\author{
Ageliki Valavanoglou ${ }^{1}$, Danijel Rebolj², and Detlef Heck ${ }^{3}$
}

\begin{abstract}
Construction projects are frequently subjected to delay and disruption leading to dispute between project participants regarding the entitlement to compensation. Challenges associated with the analysis of delay and disruption and the subsequent preparation of the claim conducted by a forensic analysis expert include the difficult retrieval of scattered, unstructured information and lack of adequate documentation, leading to weak analysis and therefore insufficient proof of causation and entitlement.

This paper illustrates the chronological information generation regarding delay and disruption in the construction phase proposing a framework based on Building Information Modelling and structured information integration, to facilitate easy filing and retrieval of relevant documentation for claim preparation.
\end{abstract}

Keywords: Delay and Disruption Claims, Documentation, Forensic Analysis, Building Information Modelling, BIM Collaboration Format.

\section{INTRODUCTION}

Disrupting events are a common occurrence in construction projects and can have a significant impact on the successful completion of a project. Disputes concerning disrupting events often arise because no party wants to accept responsibility for the extra cost incurred. The resolution of this kind of disputes lies within the clear demonstration of causation, entitlement and quantification of the disrupting event (Nguyen 2007; Klanac and Nelson 2004).

Project documentation is one of the most important information resources for the analysis of delay and disruption. As projects vary in size, duration, complexity and therefore number of participants involved throughout the lifecycle of a project, gathering relevant documentation can be a very time consuming task (Vidogah and Ndekurgi 1997).

In the construction industry documentation is often regarded as unnecessary or superfluous (Kangari 1995), but due to the multitude of alternating participants in the different project phases it is essential to retain an intact information chain to avoid significant information loss.

Research as well as the industry have tried to address the issue of documentation by proposing various optimization methods. Early attempts were limited to manual paperbased methods but within the last two decades focus has continually shifted to digitalization (Feng et al 2010).

PhD candidate, Faculty of Civil Engineering Sciences, Institute of Construction Management and Economics, Graz University of Technology, Graz, Austria, a.valavanoglou@tugraz.at

2 Professor, Faculty of Civil Engineering, Transportation Engineering and Architecture, University of Maribor, Maribor, Slovenia, danijel.rebolj@um.si

3 Professor, Faculty of Civil Engineering Sciences, Institute of Construction Management and Economics, Graz University of Technology, Graz, Austria, detlef.heck@tugraz.at 
Building Information Modelling (BIM) has brought on a new era of digitalization in the construction industry offering novel opportunities for well-structured information integration in every project phase. The preparation of delay and disruption claims is a specific area that can greatly benefit from information stored in an as-built BIM since the analysis is seldom conducted contemporaneous to the disrupting events (Vidogah and Ndekurgi 1997) but is rather left for the end of the construction phase (Hegazy 2005).

The next sections of this paper summarise an extensive literature review covering the areas related to delay and disruption claims highlighting the challenges of delay and disruption analysis and the necessary documentation for claim preparation. Furthermore, a framework is presented for BIM based information integration to support a claim, aiming to alleviate the distrust in new presentation methods.

\section{CONSTRUCTION DELAY AND DISRUPTION CLAIMS}

A delay occurs when the contractual completion date is not identical to the actual completion date of the construction project (Lee et al. 2005, Doughery 2015). Disruption occurs when an event leads to efficiency loss of the planned productivity, leading to increased difficulty of performance, cost and possibly delay (Finke 1997, Keane et al. 2008).

Arditi and Pattanakitchamroon (2008) analysed 58 cases and identified the six most frequent reasons of time-based claims:

1. Differing site conditions

2. Defective design/specifications

3. Change orders/additional work

4. Unusually severe weather conditions

5. Suspension/ stop work order

6. Late approval/submittal of drawings

Effects of delay and disruption can be diverse and must be individually identified and analysed. Compensation of delay and disruption incurred cost may include increased home office overhead, additional cost of labour, material and equipment (Schwarzkopf 1995, Haese et al. 2001).

\subsection{Documentation for delay and disruption claim preparation}

Information generation in complex projects can be extensive and the challenge is not only to ascertain that all participants carry out the obligatory documentation but also that it is stored systematically for easy retrieval. Retrieval of all relevant documents is the first step in claim preparation not only in order to gain insight into the events leading to delay and disruption and their causal link but also for a methodical preparation of the claim.

Braimah and Ndekurgi (2009) identified obstacles to the use of delay analysis methods ranking 'lack of adequate project information' in first place and 'poorly updated programmes' in second place.

The documentation requirements for the impact assessment of a disrupting event include accuracy through continuous updates, systematic structure, a high level of detail, and a comprehensive composition (Reister 2007). These characteristics have to be applied to the following elementary construction progress documentation forms (e.g., Reister 2007; Trauner et al. 2009; Vygen 2011):

- Disruption notification. The contractor is required to notify the owner of a disrupting event as soon as possible. The necessary information includes but is not 
limited to the cause of the delay or disruption (e.g. weather conditions, disruption through third party, and lack of required documents), start and end of event and extent of disruption on resources.

- Documentation of the performance change. Depending on the contract and disruption type this could be for example a comparison of the tender drawings and the actual construction work drawings.

- Representation in the construction schedule. Comparison between the as-planned and the as-built schedule and demonstration of the effects in downstream activities placing particular emphasis on the critical path. The analysis can only be successful in case of realistic baseline schedules.

- Allocated resources. Demonstration of the variance between the planned baseline productivity and the actual productivity as well as a detailed inventory of all allocated resources (personnel, material, equipment and machines). A comparison of the planned productivity rate with a similar project in size and complexity is a common argumentative method.

- Daily construction site reports. They should not be overloaded with data but should include specific information about the date, external circumstances of the construction site (e.g. weather conditions), assigned resources (e.g. labour, material, machines and equipment, subcontractors, etc.) daily work schedule (e.g. day and night shifts), activities, inspections and all relevant events on the construction site.

- Photos. Photo documentation with date and time stamps is undisputable evidence and especially significant in case of defective work, construction progress and chronological representation of events.

- Consultation meeting reports. Consultation reports are protocols of important information and decisions of the owner and his consultants regarding coordination of project participants, construction details, construction progress and possible delay and disruption occurrences and their mitigating measures.

- Relevant correspondence. E-Mail has become one of the most used forms of correspondence in recent years but important documentation and information is still delivered in paper form.

- Change orders and request for information submittal and respond lists. These lists become especially important in case of frequent change orders that significantly disrupt the planned construction schedule.

After retrieval of all relevant documents the second step in claim preparation includes the comparison of the as-planned and the as-built, the identification of the discrepancies and the analysis of the causal link between events and their effects.

\subsection{Challenges of delay and disruption analysis}

The challenge of delay and disruption analysis does not only lie within the proof of causation and quantification of the delay and damages incurred (Williams et al. 2003) but also the distinct separation and identification of the root causes and their primary and secondary effects leading to direct and indirect damages (Doughery 2015). For example, a secondary effect of unplanned work interruption due to change orders from the owner, could be a decrease in planned productivity through loss of the familiarisation effect. In order to avoid this event leading to delay of the activity and consequently to the completion date of the project, acceleration measures would have to be adopted by the 
contractor. This example shows the necessity for continuous detailed documentation. If the contractor failed to document the decline of the productivity rate it will be impossible to receive compensation for the cost incurred through the acceleration measures.

A complex construction project should be accompanied from a plethora of qualitative documentation that can support a claim in case of delay and disruption. The connection of the events and the establishment of the relationships representing the causal link of events is intricate and can be especially difficult in paper-based mode of presentation and the communication of the findings to a third party (Gibbs et al. 2013).

\section{BUILDING INFORMATION MODELLING AND DELAY AND DISRUPTION ANALYSIS}

BIM is the collaborative planning and construction method as well as the integrated model of the building, including the building process information. BIMs have several levels of development commonly described in terms of dimensions, linking the three-dimensional (3D) model to additional information and data of the project, producing additional management parameters to n-dimensional extensions (Azhar 2011). A four-dimensional (4D) BIM links building components from the 3D model to the construction schedule simulating construction sequences with integrated dependencies of processes and resources. Respectively the fifth (5D) and the sixth dimensions (6D) represent the integration of cost and construction lifecycle information (Kensek 2014).

$4 \mathrm{D}$ BIM has rendered the identification of time-space conflicts through visual inspection relatively easy in comparison to traditional 2D drawings and their shortcomings in relation to optimal use of workspace allocation (Jongeling et al. 2008). There is a variety of commercial software providing $4 \mathrm{D}$ schedule solutions with integrated object recognition and assigned categories and materials which offer visualizations of the construction sequence, workspace conflicts and detection of hidden flaws of the planned schedule (Dang et al. 2015). Furthermore, BIM tools are able to detect inconsistencies on level of detail amongst activities, omissions and errors in the schedule logic as well as identify potential accessibility problems on the construction site (Koo and Fischer 2000). 5D BIM enables cost control (Wang et al. 2014) and can be especially useful for the demonstration of cost progression throughout the phases of a project. Further collaboration between project participants was enhanced with the introduction of the BIM Collaboration Format (BCF) in 2010, enabling communication in form of structured description of issues that can arise during the planning and construction phases. The issues and relevant information can be linked to the relative objects and areas in the BIM to facilitate easy administration and retrieval (buildingSMART 2014b).

Researchers have already identified the potential of BIM in dispute prevention and dispute resolution (Greenwald 2012) as well as forensic schedule analysis. Some have concentrated on visualization, which can aid the demonstration of actual versus planned construction process in standalone or preferably comparative 4D models, highlighting the discrepancies resulting in delay and disruption (Pickavance 2007, Gibbs et al. 2013), as well as outline the integration of 4D Modeling tools into typical schedule analysis steps (Coyne 2008).

Gibbs et al. (2016) conducted a unique study on 4D BIM investigating how it can assist in proactive management of delays and improve the representation of claim information. 50 practicing Royal Institute of Chartered Surveyors adjudicators were presented with background information of the topic and the opportunities of interactive modes of 
presentation supported by computer-generated exhibits (CGEs), such as videos of virtual construction sequences. The study findings highlighted the importance of 'displaying only facts' in CGEs, 'keeping it as simple as possible', 'providing the participants with the supporting information' as well as the presence of an accompanying 'narrative from the CGE creator'. The study also showed that there is still an element of distrust in this kind of presentation methods and therefore in the accuracy of the supporting facts, highlighting the importance of the factual evidence in the preparation of claims especially in case of claims supported by visualisations.

The next section describes a framework for BIM based information integration to be used as factual evidence supporting a claim, aiming to alleviate the distrust in new presentation methods.

\subsection{Framework for BIM based information integration for delay and disruption claim preparation}

The following framework describes the integration of necessary information for the preparation of a delay and disruption claim. Figure 1 illustrates the chronological progress of claim-related information generation throughout the lifecycle of a construction project up until the end of the construction phase.

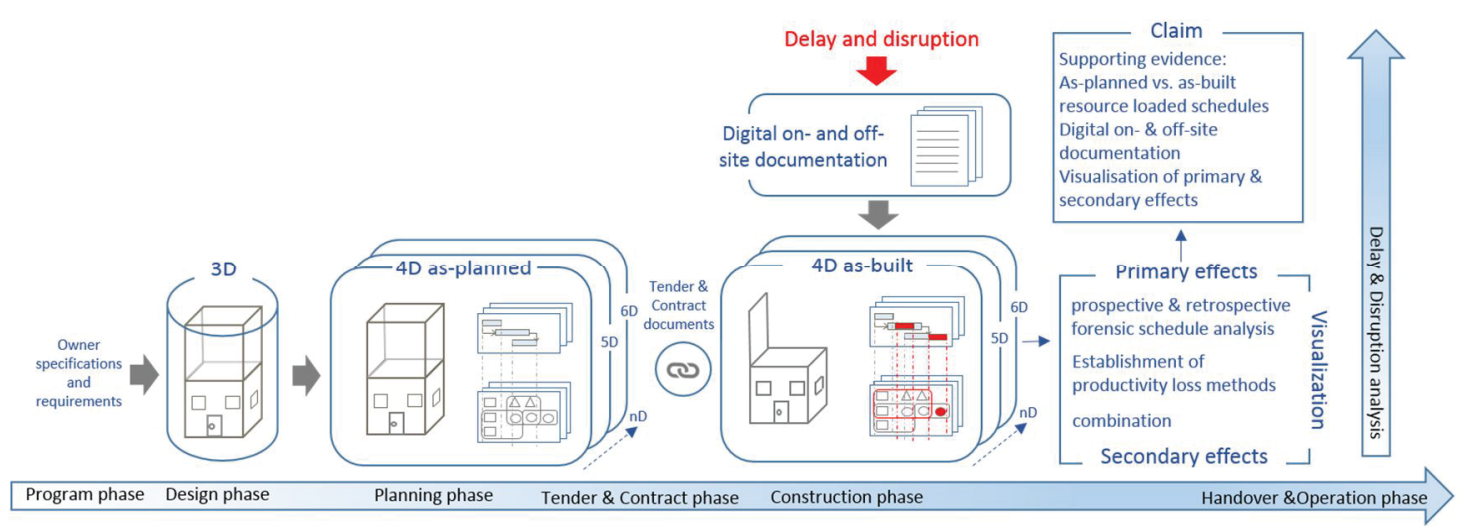

Figure 1: Chronological sequence of BIM based claim preparation

Particular focus is placed on the comparison of the as-planned versus the as-built schedule with the allocated resources for the identification and visualisation of the discrepancies in time and cost. Primary effects are analysed with conventional prospective and/or retrospective forensic schedule analysis methods and methods to demonstrate damages resulting from disruption (e.g., Barry 2008). The information for the analysis is provided by digital on- and off-site documentation.

Figure 2 depicts in greater detail the process of claim preparation based on contemporaneous information stored in the BIM and the essential delay and disruption documentation reported during the construction phase. 


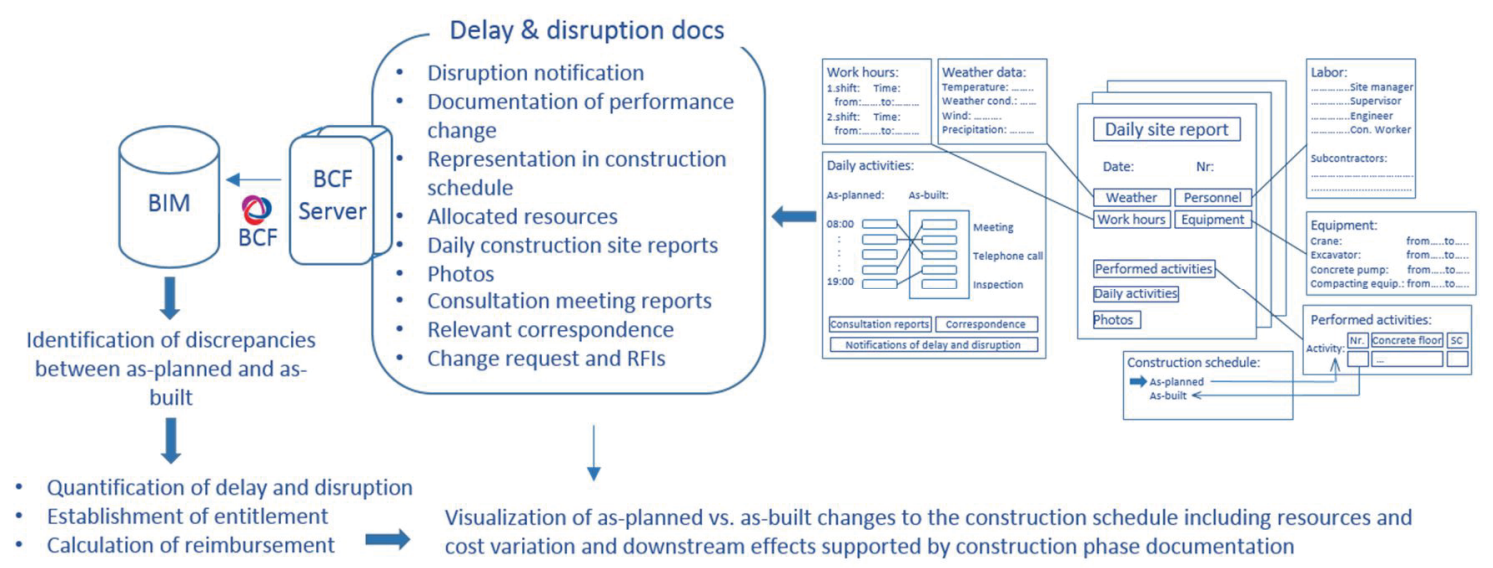

Figure 2: BIM based information integration for delay and disruption analysis

The necessary documentation, as previously discussed, should describe the conditions of the construction site and the activity status at a given point in time. The digitalisation of information from the multitude of alternating project participants through the phases of a project in a BIM, together with additional documentation stored in a BCF Server can act as a centralised, structured, object-oriented information container.

The stored information alone is not enough to form a claim. The forensic analysis expert continues to play a significant role in the analysis of events through the documented information. The benefits through the implementation of BIM and therefore the new process of information acquisition necessary to support a claim has aroused the need for a new hybrid model of forensic analyst. Analysis of delay and disruption with BIM requires an expert who has experience in forensic analysis and is familiar with the software, in order to be able to determine the accuracy of the data produced. The challenge for the analyst is to use all tools provided to identify the cause of the delay or the disruption, appoint the liability to the responsible party and calculate the damages. BIMs can store a high level of project information, producing great quantities of data. The role of the analyst is to retrieve and identify the relevant facts from the great quantities of data stored and simulated in the model, in order to support his findings.

\section{CONCLUSIONS}

The evolution of digitalisation has opened up great opportunities regarding information administration. BIM is a method that has revolutionised information integration in the construction industry with researchers and industry intently exploring its potential. This paper illustrated the capabilities of BIM regarding delay and disruption, describing the information integration necessary for analysis and demonstration of causation and entitlement to support a claim.

Further research is necessary in order to test this conceptual framework and identify its implementation potential and its limitations as well as establish the workflow for BIM based delay and disruption analysis and claim preparation.

\section{REFERENCES}

Arditi, D. and Pattanakitchamron, T. (2008). Analysis Methods in Time-Based Claims. ASCE J. Constr, Eng. Manage., 134(4), pp. 242-252, doi: 10.1061/(ASCE)07339364(2008)134:4(242). 
Azhar, S. (2011). Building Information Modeling (BIM): Trends, Benefits, Risks, and Challenges for the AEC Industry, ASCE Leadership Manage. Eng., 11, 241-252, doi: 10.1061/(ASCE)LM.1943-5630.0000127.

Braimah, N. and Ndekurgi, I. (2009). Consultants' Perceptions on Construction Delay Analysis Methodologies. ASCE J. Constr, Eng. Manage., 135, pp. 1279-1288, doi: 10.1061/(ASCE)CO.1943-7862.0000096.

buildingSMART (2014b): BIMCollaboration Format v2.0 Technical Documentation. Available at: https://github.com/BuildingSMART/BCF/tree/master/Documentation [Accessed 9. Nov. 2016].

Coyne, K. (2008). Leveraging the power of $4 D$ models for analyzing and presenting CPM schedule delay analysis. In: 2nd AACE International Annual Meeting, Toronto: AACE International.

Dang, T. and Bargstädt, H. (2015). 4D Relationships: The Missing Link in 4D Scheduling. ASCE J. Constr. Eng. Manage., doi: 10.1061/(ASCE)CO.1943-7862.0001007, 04015072.

Dougherty, J.M. (2015). Claims, Disputes and Litigation Involving BIM. London: Routledge, Taylor \& Francis Group.

Feng, C., Chen, Y. and Huang, J. (2010). Using the MD CAD model to develop the timecost integrated schedule for construction projects. Elsevier Automation in Construction, 19(3), pp. 347-356, doi: 10.1016/j.autcon.2009.12.009.

Finke, M.R. (1999). Window Analysis of Compensable Delays. ASCE J. Contr. Eng. Manage., 152(2), pp. 96-100, doi: 0.1061/(ASCE)0733-9364(1999)125:2(96).

Gibbs, D.J., Emmitt, S., Ruikar, K. and Lord, W. (2013). A case study investigation into the use of computer generated visualisations to assist with construction delay claims. In: 19th International CIB World Building Congress. Brisbane: Queensland University of Technology, pp. 1-12

Gibbs, D.J., Emmitt, S., Ruikar, K. and Lord, W. (2014). Recommendations on the Creation of Computer Generated Exhibits for Construction Delay Claims, Construction Law Journal, 30(4), pp. 236-248.

Gibbs, D.J., Lord, W., Emmit, S. and Ruikar, K. (2016). Interactive Exhibit to Assist with Understanding Project Delays. ASCE J. Leg. Aff. Dispute Resolut. Eng. Constr., doi: 10.1061/(ASCE)LA.1943-4170.0000198.

Greenwald, N. (2013). A Creative Proposal for Dispute Systems Design for Construction Projects Employing BIM. ASCE Journal of Legal Affairs and Dispute Resolution in Engineering and Construction, 5, pp. 2-5, doi: 10.1061/(ASCE)LA.1943-4170.0000106.

Haese, G. and Dragelin, T. (2001). Types of claims. In: Cushman, R.F., Carter, J.D., Gorman, P.J. and Coppi, D.F., ed., Proving and Pricing Construction Claims, 1st ed, New York: Aspen Law \& Business.

Hegazy, T., Elbeltagi, E. and Zhang, K. (2005). Keeping Better Site Records Using Intelligent Bar Charts. ASCE J. Constr. Eng. Manage., 131(5), pp. 513-521, doi: 10.1061/(ASCE)0733-9364(2005)131:5(513).

Jongeling, R., Kim, J., Fischer, M., Mourgues, C. and Olofsson, T. (2008). Quantitative Analysis of Workflow, Termorary Structure Usage, and Productivity using 4D Models. Elsevier Automation in Construction, 17, pp. 780-791, doi: 10.1016/j.autcon.2008.02.006.

Kangari, R. (1995). Construction Documentation in Arbitration. ASCE J. Constr. Eng. Manage., 121(2), pp. 201-208, doi: 10.1061/(ASCE)0733-9364(1995)121:2(201).

Keane, P.J. and Caletka, A.F. (2008). Delay Analysis in Construction Contracts., Oxford: Wiley-Blackwell.

Kensek, K.M. (2014). Building Information Modeling. 1st ed, Abingdon: Routledge, UK. 
Klanac, G.P. and Nelson, E.L. (2004). Trends in Construction Lost Productivity Claims. ASCE J. Prof. Issues Eng. Educ. Pract., 130(3), pp. 226-236, doi: 10.1061/(ASCE)10523928(2004)130:3(226).

Koo, B. and Fischer, M. (2000). Feasibility Study of 4D CAD in Commercial Construction. ASCE J. Constr. Eng. Manage., 126(4), pp. 251-260, doi: 10.1061/(ASCE)07339364(2000)126:4(251).

Lee, H., Ryu, H., Yu, J. and Kim, J. (2005). Method for Calculating Schedule Delay Considering Lost Productivity. ASCE J. Constr. Eng. Manage., 131(11), pp. 1147-1154, doi: 10.1061/(ASCE)0733-9364(2005)131:11(1147).

Nguyen, L.D. (2007). The dynamic of float, logic, resource allocation, and delay timing in forensic schedule analysis and construction delay claims. PhD. University of California, Berkley.

Pickavance, K. (2007). Using advanced forensic animations to resolve complex disruption claims, Society of Construction Law, [online]. Available at: https://www.scl.org.uk/papers/using-advanced-forensic-animations-resolve-complexdisruption-claims [Accessed 11 Oct. 2016].

Reister, D. (Ed.). (2007). Nachträge beim Bauvertrag. 2nd ed. Neuwied: Werner, Germany. Schwartzkopf, W. (1995). Calculating Lost Labour Productivity in Construction Claims. New York: John Wiley \& Sons..

Trauner, T.J. (2009). Construction Delays: documenting causes, winning claims, and recovering costs. 2 nd ed. Amsterdam: Elsevier.

Vidogah, W. and Ndekugri, I. (1997). Improving Management of Claims: Contractor's Perspective. ASCE J. Manage. Eng., 13(5), pp. 37-44, doi: 10.1061/(ASCE)0742597X(1997)13:5(37).

Vidogah, W. and Ndekugri, I. (1998). A review of the role of information technology in construction claims management. Elsevier Computers in Industry, 35(1), pp. 77-85, doi: 10.1016/S0166-3615(97)00085-7.

Vygen, K., Joussen, E., Schubert, E. and Lang, A. (2001). Bauverzögerung und Leistungsänderung: Rechtliche und baubetriebliche Probleme und ihre Lösungen, 6th ed. Cologne: Werner.

Williams, T., Ackermann, F. and Eden, C. (2003). Structuring a delay and disruption claim: An application of cause-mapping and system dynamics, Elsevier European Journal of Operational Research, 148(1), pp. 192-204, doi: 10.1016/S0377-2217(02)00372-7. 